\title{
Psychophysical scaling of the prism diopter unit
}

\author{
JOSEPH N. TRACHTMAN and ROBERT F. DIPPNER \\ State University of New York, State College of Optometry, New York, New York 10010
}

\begin{abstract}
The relation between actual and perceived prism displacement was investigated for monocular and haploscopic conditions. Five subjects made estimates of the displacement of 10 prisms ranging in power from .76 to 21.03 prism diopters. The power exponent for both monocular and haploscopic conditions approximated unity. The demonstration that perceived prism displacement is a ratio scale will allow the treatment of tests of monocular and haploscopic prism displacement by parametric statistics.
\end{abstract}

In vision research and eye care facilities, prisms are utilized frequently for a variety of tests and measurements. In vision research, prisms are frequently used in perceptual adaptation experiments (Coren, 1966; Harris, 1965; Welch, 1971; Wallace, Note 2), while, in the clinic, prisms are primarily used in the prism cover test, ranges of vergence, the prism-rack after-image test, and the monocular prism jump test (Borish, 1970). The statistical interpretation of prism measurements has been discussed by Pierce (1968). Pierce noted that the current knowledge of the psychophysical scale for the prism diopter is limited to an ordinal scale.

The purpose of the present experiment was to determine a psychophysical scale for perceived prism displacement. The study consisted of two major components: (1) monocular scaling of prism displacement and (2)haploscopic scaling of prism displacement.

In monocular prism scaling, the experimental task was to give the numerical estimate of the distance between two points viewed with one eye. In haploscopic scaling, the task was the same but with each point being seen by a different eye. Such a procedure has been suggested by Pierce (1968), but no previous experiments in the literature have considered magnitude estimation for haploscopically viewed prism displacement.

\section{METHOD}

\section{Subjects}

Subjects were five males in their mid-20s, associated with the New York State College of Optometry. The subjects were unaware of the exact nature of the experiment. Each subject was given an optometric examination at the end of the experiment. All subjects had measurements within normal limits. ${ }^{1}$

\section{Apparatus}

The subject was seated at a table with his head in a headrest so that his right eye was behind a beam splitter. Distal to the beam splitter was a wheel with wedge prisms attached along its perimeter. The prisms were of the following powers: $.76 \mathrm{pd}$, $1.28 \mathrm{pd}, 2.06 \mathrm{pd}, 3.20 \mathrm{pd}, 4.09 \mathrm{pd}, 5.12 \mathrm{pd}, 8.00 \mathrm{pd}, 10.12 \mathrm{pd}$, $12.25 \mathrm{pd}$, and $21.03 \mathrm{pd}$. Also along the perimeter of the wheel were a plano rectangle of Plexiglas of $0 \mathrm{pd}$ and an open notch The power of each prism was determined by measuring its

Dean Yager sponsors this paper and takes full editorial responsibility for its content.

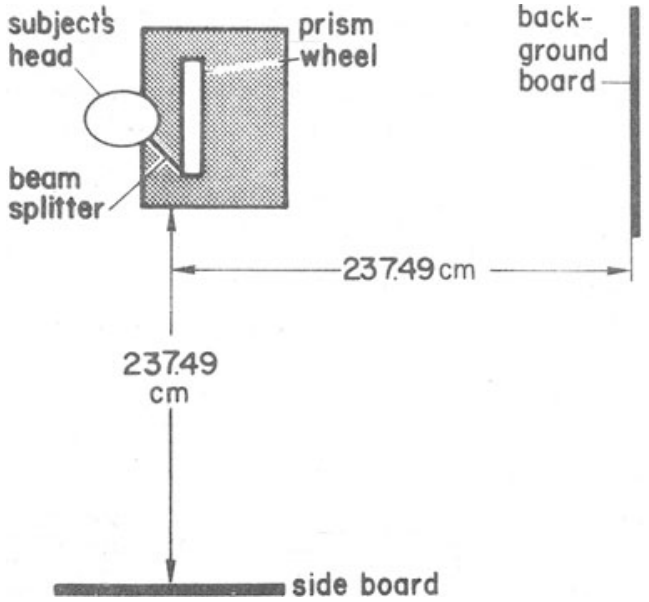

Figure 1. Apparatus.

deviation of a slit of light of wavelength $589 \mathrm{~nm}$ on a tangent screen.

A square background board, which subtended $27.2 \mathrm{deg}$ of visual angle, was supported in a vertical position by an easel. A slide box was attached to the center of the board with a $35-\mathrm{mm}$ film negative of five alternating black and white stripes along the front edge. Each stripe subtended $3.3 \mathrm{~min}$ of visual angle and was $53 \mathrm{~min}$ of visual angle in height. The slide box was illuminated by a $6-\mathrm{V}$ bulb inside the slide box. The luminance of the slide was $21.8 \mathrm{~cd} / \mathrm{m}^{2}$ as measured with an SEI photometer.

Another screen was located $90 \mathrm{deg}$ to the right of the headrest, subtending 14.2 deg of visual angle horizontally and $6.1 \mathrm{deg}$ of visual angle vertically. Immediately above this screen was an 8 -W black light fixture and tube (Edmund Scientific, No. 71,274). Both the side screen and the background board were equidistant from the subject's eye. A thumbtack head, painted fluorescent orange, which subtended $10.6 \mathrm{~min}$ of visual angle, was fixed onto the center of the side screen. The luminance of the tackhead with the room lights out and the black light on was also $21.8 \mathrm{~cd} / \mathrm{m}^{2}$.

To eliminate stray light, all the experimental apparatus was painted flat black, and the room windows were blacked out.

An electronic circuit provided: (1) lighting for the experiment and (2) a timer to control the lighting of the slide box.

\section{Procedure}

The subject, with a patch over his left eye, was instructed to sit with his head in the headrest. The wheel of prisms was adjusted so that the rectangular grid (the striped slide) appeared in the center of the open notch in the wheel of prisms. The overhead room light was then turned off. 


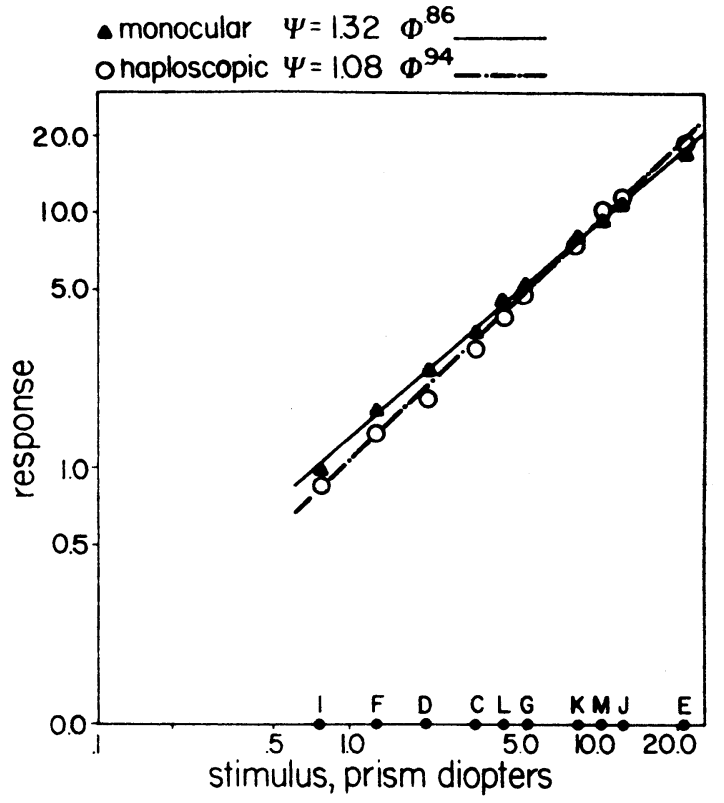

Figure 2. Group data.

The orange thumbtack head on the side screen was then moved by the experimenter until the subject reported that the orange tack head appeared directly in the middle of the rectangular grid. The tack was then moved vertically until it appeared, to the subject, to be tangent to the top edge of the rectangular grid. This was the zero position.

The directions were then read to the subject: (1) The rectangular grid will now be turned off. (2) You are to look at the orange dot. (3) The rectangular grid will now be turned on, and you will be shown a horizontal distance from the orange dot to the rectangular grid; this distance will be called "10." (The subject was shown the $10.12 \mathrm{pd}$ displacement twice.) (4) You will now be presented with a series of distances from the orange dot to the rectangular grid, for example, if the distance appears half as much as the " 10 " distance, call it 5 ; if it appears twice as much as the "10" distance, call it 20. (5) You can use any number, whole, decimal, or fraction to express the distance you see. (6) You will be shown each distance for only $4 \mathrm{sec}$ so make you judgments as quickly as possible.

The subject was told that all questions would be answered at the end of the experiment.

After the first four series of monocular magnitude estimations were made, the patch was removed from subject's left eye. The prism wheel was moved so that the prisms would align in front of the subject's left eye. The grid and orange dot were aligned as for the monocular estimations. The same directions were then read to the subject with the addition of: (7) After each displacement is assigned a number, I will check to make sure that the grid and the orange dot are still aligned. (Frequent checking of alignment was made to compensate for phoria drifts.)

For each prism, there were six haploscopic magnitude estimates made. When the haploscopic estimates were completed, two additional series of monocular estimates were made under the same conditions as the first series of estimates. For both monocular and haploscopic conditions, the prisms were presented in random order.

A rectangle of plano Plexiglas was used to monitor alignment of the dot and grid during the experiment. The Plexiglas rectangle was included in the random sequence of prism presentations. In the monocular condition, all subjects reported a value of zero, indicating alignment of the dot and grid, when the Plexiglas rectangle was presented after each prism presentation. If the subject reported any number other than zero, the experimenter realigned the grid and dot to the zero position. The Plexiglas rectangle was also included in the random sequence of haploscopic presentations. Again, if the subject reported any number other than zero, the experimenter realigned the grid and dot to the zero position. Because of these checks on alignment, the interresponse time varied from subject to subject.

\section{RESULTS}

For each subject and for each of the three conditions, (1) monocular viewing with four estimations, (2) monocular viewing with two estimations, and (3) haploscopic viewing with six estimations, the geometric mean of each prism's displacement was calculated (Engen \& Levy, 1955; Stevens, 1962).

A line of best fit was calculated for each set of data points. The slope of the line is equal to the exponent of the power function. Minimum sum of squares of the residuals was the criterion for a line of best fit. The formula

$$
\Psi=\mathrm{k}\left(\emptyset-\emptyset_{\mathrm{o}}\right)^{\mathrm{n}}
$$

was utilized in the calculations: $\varphi_{0}$ being the threshold correction factor. To find a line of best fit, $\phi_{o}$ and $n$ were varied until the criterion was achieved (Kalikow, Note 1). In addition to testing for fit to a power curve, lines of fit for the data were tested to a straight line, an exponential curve, and hyperbolic curves. Using the criterion of a minimum of percent different difference hetween the actual $\mathrm{Y}$ values and the predicted $\mathrm{Y}$ values, the data consistently fit the power curve best. All the above calculations were performed on a PDP-10 computer.

The range of the power function for the monocular estimates for subjects was from .77 to 1.04 , with the geometric mean of the group data being .86. The range of the power function for the haploscopic estimates for subjects was from .87 to 1.10 , with the geometric mean of the group being 94 .

A comparison of monocular and haploscopic lines of best fit was made to determine if the exponents were significantly different from each other. Two tests were utilized: (1) a t test for correlated data, and (2) each geometric mean of the monocular estimates was subtracted from the haploscopic estimates. The difference was plotted against the power of the prisms. The results of both of these tests showed that the lines were not significantly different from each other.

\section{DISCUSSION}

The power functions for both monocular and haploscopic prism displacements were found to approximate unity.

The experimental task involved in monocular magnitude estimation of prism displacement is similar to the task involved in magnitude estimation of line length. The task is to give the numerical estimate of a distance in the frontal plane. Therefore, 
a similarity in exponents between magnitude estimation of line length and monocular prism displacement would be expected. For prisms of small powers, as used in this experiment, the original and displaced images are virtually coplanar. The largest difference in plane position was with the $21.03 \mathrm{pd}$ prism, the difference being only $2 \%$. The exponent of the powicr function for magnitude estimation of visual length has been found to be approximately 1, ranging from .89 to 1.09 (Engen \& Ross, 1966; Stevens, 1957, 1962, 1971: Teghtsoonian \& Teghtsoonian, 1971). The exponent of the power function for monocular magnitude estimation of prism displacement in the present study was found to be .86 , ranging from .77 to 1.04 .

The experimental task involved in magnitude estimation of haploscopic prism displacement is to give the numerical estimate of the distance between two points in the frontal plane, each point being seen by a different eye. While the experimental method in the haploscopic condition was not precisely the same as involved in the monocular condition. the power function for the haploscopic magnitude estimation was similar to the power function for monocular estimation. The average exponent for the haploscopic condition was .94 , ranging from .87 to 1.10 . A t test between the monocular and haploscopic conditions showed no significant difference between the exponents. By comparing the results of the present experiment, both monocular and haploscopic conditions, with the results of magnitude estimation of line length, it can be seen that the power functions were quite similar and that the power function was approximately one.

In summary, the results of the present experiment have demonstrated the ratio scale nature of haploscopic and monocular prism displacements. Therefore, it can now be stated that perceptually, $4 \mathrm{pd}$ displace an object twice as much as $2 \mathrm{pd}$ and half as much as $8 \mathrm{pd}$.

\section{REFERENCE NOTES}

1. Kalikow, D. N. A group of computer programs for the analysis of direct psychophysical scaling data: Its development and application to a problem in vibration perception. Doctoral dissertation, Brown University, Ann Arbor, Michigan. University Microfilms, 1970.
2. Wallace, $B$. The role of visual boundaries in adaptation to prismatic viewing. Paper presented at the meeting of the Midwestern Psychological Association, Chicago, May 1973.

\section{REFERENCES}

Borish, I. Clinical refraction (3rd ed.). Chicago: Professional Press, 1970.

Coren, S. Adaptation to prismatic displacement as a function of the amount of available information. Psychonomic Science, $1966,4,407-408$.

Engen, T., \& Levy, $N$. The influence of standards on psy chophysical judgments. Perceptual and Motor Skills, 1955, $5,193-197$.

Engen, T., \& Ross, B. Effect of reference number on magnitude estimation. Perception \& Psy chophy sics, 1966, 1, 74-76.

Harris, C. S. Perceptual adaptation to inverted, reversed and displaced vision. Psychological Review, 1965, 72, 419-444.

Pierce, J. R. Research design, statistics, and interpretation.

Duncan, Okla: Optometric Extension Program, 1968.

Stevens, S. S. On the psy chophysical law. Psy chological Review, $1957,64,153-181$.

Stevens, S. S. The surprising simplicity of sensory metrics. American Psy chologist, 1962, 17, 24-39.

Stevens, S. S. Issues in psychophysical measurement. Psychological Review, 1971, 78, 426-450.

Teghtsoonian, M., \& Teghtsoonian, R. How repeatable are Stevens' power laws for individual subjects? Perception \& Psychophysics, 1971, 10, 147-149.

Welch, R. B. Prism adaptation: The "target-pointing effect" as a function of exposure trials. Perception \& Psychophysics, $1971,9,102-104$.

\section{NOTE}

1. During the optometric examination, no signs of aniseikonia were found. The greatest amount of anisometropia was 1 diopter, and all keratometric readings were \pm .75 diopter of the fellow eye. The presence of aniseikonia would produce a difference in magnification between the two eyes. A magnification difference could cause a difference in perceived distance between one eye and the other 